\title{
UM EXEMPLO DE "DISTRIBUIÇÃO SOCIAL DA MENTE” EM UMA AULA DE FÍSICA QUÂNTICA
}

\author{
An example of the "social distribution of the mind" \\ in a quantum physics lesson
}

\author{
Alexsandro Pereira de Pereira ${ }^{1}$. Fernanda Ostermann ${ }^{2}$. \\ Cláudio José de Holanda Cavalcanti ${ }^{3}$
}

Resumo: Diversos estudos em psicologia, antropologia e sociologia desenvolveram a concepção na qual a mente é vista como algo que "se estende além da pele". O presente trabalho apresenta, no âmbito do ensino de física quântica, uma investigação sobre a distribuição social da mente a partir da análise de uma atividade desenvolvida com um grupo de graduandos em Física, mediada por um interferômetro virtual de Mach-Zehnder. Nossa análise mostrou que, nos debates mais polêmicos, a construção de significados na atividade surgiu por meio de um processo complexo de interanimação de vozes, no qual é impossível determinar quem solucionou o problema, assinalando um ou outro indivíduo isoladamente - isto é, foi o grupo, enquanto "sistema", que desempenhou tal função no plano intermental.

Palavras-chave: Cognição distribuída. Abordagem sociocultural. Ensino de física quântica.

\begin{abstract}
Several studies in psychology, anthropology and sociology have developed a notion in which the mind is viewed as something that "extends beyond the skin". This paper presents, in the context of quantum physics learning, a study of the social distribution of mind through the analysis of a task carried out by a group of undergraduate physics students, mediated by a virtual Mach-Zehnder interferometer. Our analysis has shown that, for most controversial debates, the meaning-making in the task came from a complex process of interanimation of voices in which it is impossible to determinate who has solved the problem by assigning one or other individual alone - i.e., the group as a "system" has played this role on the instrumental plane.
\end{abstract}

Keywords: Distributed cognition. Sociocultural approach. Learning of quantum physics.

\footnotetext{
${ }^{1}$ Doutorado em Ensino de Física, Programa de Pós-Graduação em Ensino de Física, Universidade Federal do Rio Grande do Sul (UFRGS). Avenida Bento Gonçalves, 9500. Porto Alegre, RS, Brasil. 91.501-970. alexsandro.pereira@ufrgs.br

${ }^{2,3}$ Departamento de Física, Instituto de Física, UFRGS. Porto Alegre, RS, Brasil.
} 
Pereira, A. P.; Ostermann, F.; Cavalcanti, C. J. H.

\section{Introdução}

A perspectiva da cognição distribuída é uma teoria baseada na tradição de Vygotsky $(1994,1996,1998)$ que encontra contrapartida em diversas outras áreas do conhecimento humano (ciência cognitiva contemporânea, psicologia cognitiva, antropologia e sociologia). De acordo com essa perspectiva, a concepção da mente fica muito limitada quando a concebemos como algo estritamente confinado dentro da cabeça. Conforme Wertsch (1991b) enfatiza, não se trata de retornarmos à noção de consciência coletiva estabelecida pela psicologia social, mas, sim, de reconhecermos os insights de autores como Vygotsky (1994, 1998), Bruner (1997), Geertz (1989), Hutchins (1995) e outros que conceberam a atividade mental como um processo completamente dependente dos aspectos físicos, sociais e culturais do ambiente em que o indivíduo está inserido.

Essa concepção da mente como algo "fora da cabeça" tem sido utilizada como quadro-teórico em diversas pesquisas em Educação, aparecendo, frequentemente, sob o rótulo de cognição distribuída. Segundo Moore e Rocklin (1998), há uma multiplicidade de interpretações vinculadas a essa perspectiva, fazendo-se necessário uma melhor precisão no uso do referido termo de modo a causar impacto significativo nas pesquisas educacionais. $\mathrm{Na}$ visão desses autores, os trabalhos pautados na perspectiva da cognição distribuída podem ser classificados em duas categorias distintas.

A primeira delas, individual-plus, concebe a mente como um fenômeno individual, mas reconhece a importante influência exercida por fatores externos ao indivíduo. Nessa abordagem, a inteligência é concebida como sendo distribuída em torno de uma variedade de artefatos e outros indivíduos. Uma questão de pesquisa pertinente a essa perspectiva é a de como o trabalho, em conjunto com outros indivíduos e artefatos, incluindo computadores, influencia nossa cognição (MOORE; ROCKLIN, 1998, p. 102). Na outra extremidade do espectro, uma posição alternativa a esta concebe o sistema cognitivo como sendo um processo puramente social, que não pode ser reduzido a construtos psicológicos individuais. Segundo essa perspectiva, denominada social-only, aprender, pensar e saber são relações entre pessoas dentro de um mundo social e culturalmente estruturado. Uma questão de pesquisa que surge dessa perspectiva é a de como as normas sociais estão dialeticamente relacionadas com a atividade de um determinado grupo (MOORE; ROCKLIN, 1998, p. 103). Conforme apontam esses autores, a maioria dos trabalhos que utilizam o termo cognição distribuída enquadra-se na categoria individual-plus.

O presente trabalho apresenta, no âmbito do ensino de física quântica, um estudo empírico sobre o fenômeno da cognição distribuída, a partir da análise de uma atividade didática desenvolvida com um grupo de graduandos em Física, e mediada por um interferômetro virtual de Mach-Zehnder (OSTERMANN; PRADO; RICCI, 2006). O objetivo desse estudo é descrever os processos intermentais que entram em cena durante a realização da tarefa, a partir de uma perspectiva sociocultural da cognição distribuída (WERTSCH, 1991a). De acordo com Wertsch (1991b), o objetivo da abordagem sociocultural é explicar a relação entre os processos mentais humanos e o contexto cultural, institucional e histórico em que esses processos têm lugar. Apesar de considerarmos nosso trabalho mais próximo à categoria individual-plus, sugerida por Moore e Rocklin (1998), procuramos ir além das categorias "indivíduo" e "grupo", evitando a antinomia indivíduo-sociedade em prol de uma análise centrada na noção de ação mediada (COLE; WERTSCH, 1996). Da maneira compreendida por Werts- 
Um exemplo de "distribuição social da mente" ...

ch (1998a, 1998b), a ação humana pode ser uma atividade externa ou interna, podendo ser conduzida tanto por grupos (pequenos ou grandes) como por indivíduos.

Para avaliar as ações dos estudantes, conforme eles progrediam na tarefa, utilizamos uma técnica de análise do discurso pautada na perspectiva sociocultural. Cabe salientar que os resultados apresentados no presente trabalho fazem parte de um estudo mais amplo que investiga o ensino de física quântica na formação inicial de professores de Física (PEREIRA, 2008; PEREIRA; CAVALCANTI; OSTERMANN, 2009; PEREIRA; OSTERMANN; CAVALCANTI, 2009a, 2009b, 2011).

\section{Abordagem sociocultural para a cognição distribuída}

De acordo com Lemke (2001), adotar a perspectiva sociocultural na pesquisa em educação em ciências significa, antes de tudo, formular questões sobre o papel da interação social, considerando-a, como na tradição vygotskyana, central e necessária para a aprendizagem, e não meramente auxiliar e secundária. Tendo em vista a natureza social das aulas de ciências, nosso ponto de partida, com relação ao marco teórico empregado no presente estudo, reside nos achados de L. S. Vygotsky $(1994,1998)$ sobre a origem social das funções mentais e sua estreita relação com o uso de instrumentos e signos (WERTSCH, 1985).

Interessados pelas mudanças introduzidas pelos signos nas funções psicológicas básicas, Vygotsky (1994) e seus colaboradores A. N. Leontiev e A. R. Luria desenvolveram um estudo sobre o fenômeno da memória indireta, que resultou na percepção de algumas atividades mentais, tais como o pensar e o lembrar, como operações socialmente distribuídas. O famoso experimento da tarefa das cores proibidas, conduzido por Leontiev (VYGOTSKY, 1994), demonstrou, com particular clareza, o papel desempenhado pelos signos nos processos de memória e atenção voluntária.

O experimento, envolvendo crianças entre cinco e 13 anos de idade, consistiu num jogo de perguntas e respostas no qual a criança era solicitada a responder 18 questões sobre seu cotidiano. Dessas 18 perguntas, sete referiam-se a cores de objetos. Exemplos de questões utilizadas no jogo são: "você tem um amigo?"; "qual é a cor da sua camiseta?”; "você já andou de trem?" (VYGOTSKY, 1994, p. 55). A seguir, em uma segunda etapa do experimento, repetia-se a tarefa impondo-se algumas restrições às respostas da criança. Para ganhar o jogo, ela tinha de evitar pronunciar o nome de determinadas cores (verde e amarelo, por exemplo) e não podia utilizar uma mesma cor duas vezes.

Após o término dessa segunda etapa, a criança recebia um conjunto de nove cartões coloridos para serem utilizados durante a atividade da forma como ela achasse adequada. A única instrução dada era a de que os cartões poderiam ajudá-la a ganhar o jogo. Finalmente, repetia-se o experimento utilizando os cartões coloridos. Os resultados obtidos por Vygotsky e Leontiev (VYGOTSKY, 1994) claramente indicaram a existência da memória mediada. Enquanto as crianças pré-escolares não eram capazes, ainda, de organizar seu comportamento a partir da utilização de estímulos externos, as crianças em um estágio posterior de desenvolvimento utilizaram, de forma sistemática, os cartões coloridos como meios auxiliares para melhorar consideravelmente seu desempenho na atividade. Esse resultado sugere que as diferenças de habilidades no uso da memória entre crianças de diferentes idades resultam não apenas do desenvolvimento de constituições mentais e nervosas vinculadas ao processo de memori- 
zação, mas, sobretudo, devido ao desenvolvimento de um método de memorização baseado no uso de signos (VYGOTSKY, 1929).

É precisamente no uso mediado de meios externos ao corpo humano, durante a organização e controle do comportamento individual, que se define a natureza distribuída da atividade mental. Para Vygotsky (1994, p. 52), a simples operação de dar um nó num laço ou marcar um pedaço de madeira no intuito de lembrar de alguma coisa, modifica a estrutura psicológica do processo de memória, estendendo-a para além das dimensões biológicas do sistema nervoso humano. Conforme sugere Wertsch (1991b), esse aspecto da mediação cultural pode ser esclarecido à luz de um exemplo proposto por Bateson (1972), cuja tradição de pesquisa é completamente distinta daquela proposta por Vygotsky (1994) e seus colaboradores:

Suponha que eu seja um homem cego e que eu use uma bengala. Eu vou tap, tap, tap. Onde eu começo? Meu sistema mental está delimitado pelo cabo da bengala? Está delimitado pela minha pele? Ele começa no meio da bengala? Ele começa na ponta da bengala? (BATESON, 1972, p. 459 , tradução nossa)

O ponto central da abordagem sociocultural de Wertsch (1991b, 1998a, 1998b) consiste em adotar a ação mediada como unidade de análise. Isso porque a ação humana envolve o uso de "ferramentas culturais", ou modos de mediação, que são fornecidos por um cenário sociocultural particular. Assim, as categorias de "ação mediada" e de "ferramentas culturais" estabelecem um vínculo entre os processos mentais humanos, de um lado, e o contexto cultural, histórico e institucional em que eles ocorrem, de outro. Partindo dessa perspectiva, Wertsch (1991b) toma emprestada, de teóricos como Geertz (1989) e Bateson (1972), a concepção na qual a mente é concebida como algo que "se estende além da pele". A mente é considerada "distribuída" em relação a dois aspectos: (a) a intrínseca relação entre os processos mentais e os instrumentos mediadores; (b) a origem social das funções mentais superiores.

De acordo com o primeiro aspecto, Wertsch (1991b) chama atenção para o fato de a mente humana estar moldada, senão definida, pelos instrumentos mediadores:

Para utilizar um exemplo contemporâneo, vamos considerar o caso de um engenheiro que projeta a carroçaria de um carro utilizando imagens desenhadas para formar opções e decidir entre elas. Faz sentido isolar o mecanismo que media a ação da ação mental do indivíduo? Com efeito, é possível que tal ação seja independente dos instrumentos mediadores? Provavelmente não. (WERTSCH, 1991b, p. 15, tradução nossa)

Conforme mostra o exemplo acima, a noção de ação envolve uma "tensão irredutível" (WERTSCH, 1998b) entre os indivíduos e os instrumentos mediadores que eles empregam, de tal forma que é impossível separar a ação dos meios utilizados para mediá-la. A ação e os meios mediacionais estão relacionados de forma tão fundamental que resulta mais adequado falar de agentes-agindo-com-ferramentas-culturais, incluindo, aqui, a linguagem e os gestos corporais, do que simplesmente falar de indivíduos (WERTSCH, 1991b).

Com relação ao segundo aspecto, de acordo com a lei genética geral do desenvolvimento cultural (VYGOTSKY, 1996; WERTSCH, 1985), as funções mentais superiores apare- 
Um exemplo de "distribuição social da mente" ...

cem, primeiramente, no plano interpsicológico (i.e., social) para só, posteriormente, aparecerem no plano intrapsicológico (i.e., individual). Em outras palavras, as operações que inicialmente representam uma atividade externa são reconstruídas internamente de modo a transformarem um processo social em um processo psicológico. Isto implica que a noção de função mental superior (e.g. lembrar) pode ser igualmente aplicada tanto a grupos como a indivíduos (WERTSCH, 1985). Para ilustramos o tipo de fenômenos que temos em mente, tomaremos emprestado o seguinte exemplo proposto por Tharp e Gallimore:

Uma criança de 6 anos de idade perdeu seu brinquedo e pede ajuda para seu pai. O pai pergunta onde ela viu o brinquedo pela última vez; A criança diz: "Eu não lembro". Ele faz uma série de perguntas: "Ele não está no seu quarto? Lá fora? No vizinho?”. Para cada pergunta, a criança responde não. Quando ele diz, "no carro?” ela diz: "Eu acho que sim" e sai para recuperar o seu brinquedo. (THARP; GALLIMORE, 1988, p. 7, tradução nossa)

Uma questão pertinente, nesse caso, é a seguinte: quem lembrou onde estava o brinquedo? De acordo com Wertsch (1991b), é impossível apontar quem o encontrou assinalando uma ou outra pessoa isoladamente. De alguma forma, a assistência do pai organizou a atividade da criança de modo a trazer à tona aquelas informações que estavam inacessíveis à sua memória. Podemos dizer que a dupla como um todo, enquanto "sistema", desempenhou a função de lembrar.

Esse processo ocorreu no plano interpsicológico através da interação social. Assim, a memória passa a ser um aspecto da atividade mental que pode ser adequadamente empregado tanto a indivíduos isolados como a duplas ou grupos maiores. $\mathrm{O}$ mesmo pode ocorrer com relação a outras dimensões da atividade mental humana, tal como a solução de problemas (WERTSCH, 1979). Conforme Cole e Wertsch (1996) apontam, essa concepção da mente distribuída, resultante dos trabalhos de Vygotsky, tem grande ressonância na ciência cognitiva contemporânea (HUTCHINS, 1995).

\section{Metodologia de pesquisa}

A presente investigação foi desenvolvida junto a uma disciplina do sétimo semestre do curso de Licenciatura em Física da Universidade Federal do Rio Grande do Sul. A disciplina em questão consiste em uma revisão conceitual de temas de física moderna e contemporânea a partir da apresentação de seminários ministrados pelos próprios estudantes. No segundo semestre de 2007, foi implementada, em sala de aula, uma atividade didática centrada no uso de um interferômetro virtual de Mach-Zehnder (OSTERMANN; PRADO; RICCI, 2006), desenvolvido por nosso grupo de pesquisa.

O interferômetro de Mach-Zehnder consiste em um experimento óptico capaz de demonstrar o fenômeno de interferência luminosa. Para experiências com fótons únicos, no entanto, esse experimento pode representar uma poderosa ferramenta didática para o ensino de física quântica (ADAMS, 1998; MÜLLER; WIESNER, 2002; PEREIRA; OSTERMANN; CAVALCANTI, 2009b; PESSOA JR., 1997; SCARANI; SUAREZ, 1998). Seu uso em simula- 
Pereira, A. P.; Ostermann, F.; Cavalcanti, C. J. H.

ção virtual se justifica pela falta de recursos nos laboratórios de ensino que possibilitem a realização do experimento em regime monofotônico, i.e., em regime em que um único fóton é emitido de cada vez pela fonte.

O objetivo de nossa pesquisa é descrever os processos interpsicológicos utilizados por um grupo de futuros professores de física ao realizar uma tarefa envolvendo conceitos de física quântica. Os estudantes presentes na atividade (11 no total) foram separados em quatro duplas e um trio. Um pequeno roteiro foi desenvolvido para guiá-los durante a atividade. Cada grupo ocupou um microcomputador equipado com o simulador virtual de interferômetro de Mach-Zehnder, microfone e gravador de som. Os diálogos estabelecidos pelos estudantes foram registrados em áudio e, posteriormente, transcritos para análise. A análise do discurso utilizada em nosso estudo é baseada na perspectiva sociocultural, e toma alguns elementos das teorias de Bakhtin (1996, 2006) e de Vygotsky $(1994,1998)$. Os resultados da análise desse grupo foram apresentados em outro trabalho (PEREIRA, OSTERMANN; CAVALCANTI, 2009a) e, portanto, não serão reproduzidos neste artigo. Ao invés disso, apresentaremos, de maneira detalhada, dois episódios vivenciados por dois grupos de estudantes que evidenciam o fenômeno da distribuição social da mente.

\section{Dois exemplos de distribuição da mente}

Nosso objetivo era estudar o fenômeno de interferometria quântica segundo a abordagem conceitual proposta por Pessoa Jr. (2005). Em nossa atividade, o interferômetro virtual foi utilizado para mediar o debate em sala de aula, especialmente nos casos em que os resultados das "experiências virtuais" se mostraram contraintuitivos. Nos diálogos apresentados a seguir, as frases em negrito representam leitura em voz alta dos enunciados do roteiro. Os erros de português e as eventuais ocorrências de linguagem coloquial foram mantidos para preservar o contexto e a autenticidade dos enunciados.

\section{Mente distribuída entre indivíduos e artefatos}

Ao interagirem com o software, Diego e Arnaldo (nomes fictícios) regularam a fonte para emitir um único fóton de cada vez. Em uma determinada etapa da atividade, os estudantes retiraram o segundo espelho semirrefletor do interferômetro e substituíram os anteparos por detectores de fóton, conforme mostra a Figura 1. Os fótons eram detectados ora no detector mais à esquerda, ora no detector mais à direita. Os estudantes eram solicitados a responder às seguintes questões: (a) É possível inferir o caminho percorrido pelo fóton? Explique; (b) O fóton é capaz de se dividir em dois "meios fótons"? Explique.

Com relação à primeira questão, a expectativa era a de que, a partir da observação da simulação, os estudantes pudessem identificar o caminho percorrido pelo fóton de acordo com o detector acionado. Na Figura 1, por exemplo, a luz acesa sobre o detector mais à direita indica que o fóton emitido pela fonte, nesse caso, foi transmitido pelo espelho semirrefletor, e, em seguida, refletido pelo espelho mais à esquerda. A interação discursiva entre os estudantes ocorreu da seguinte maneira: 
Um exemplo de "distribuição social da mente" ...

Figura 1. Verificando a indivisibilidade dos fótons.

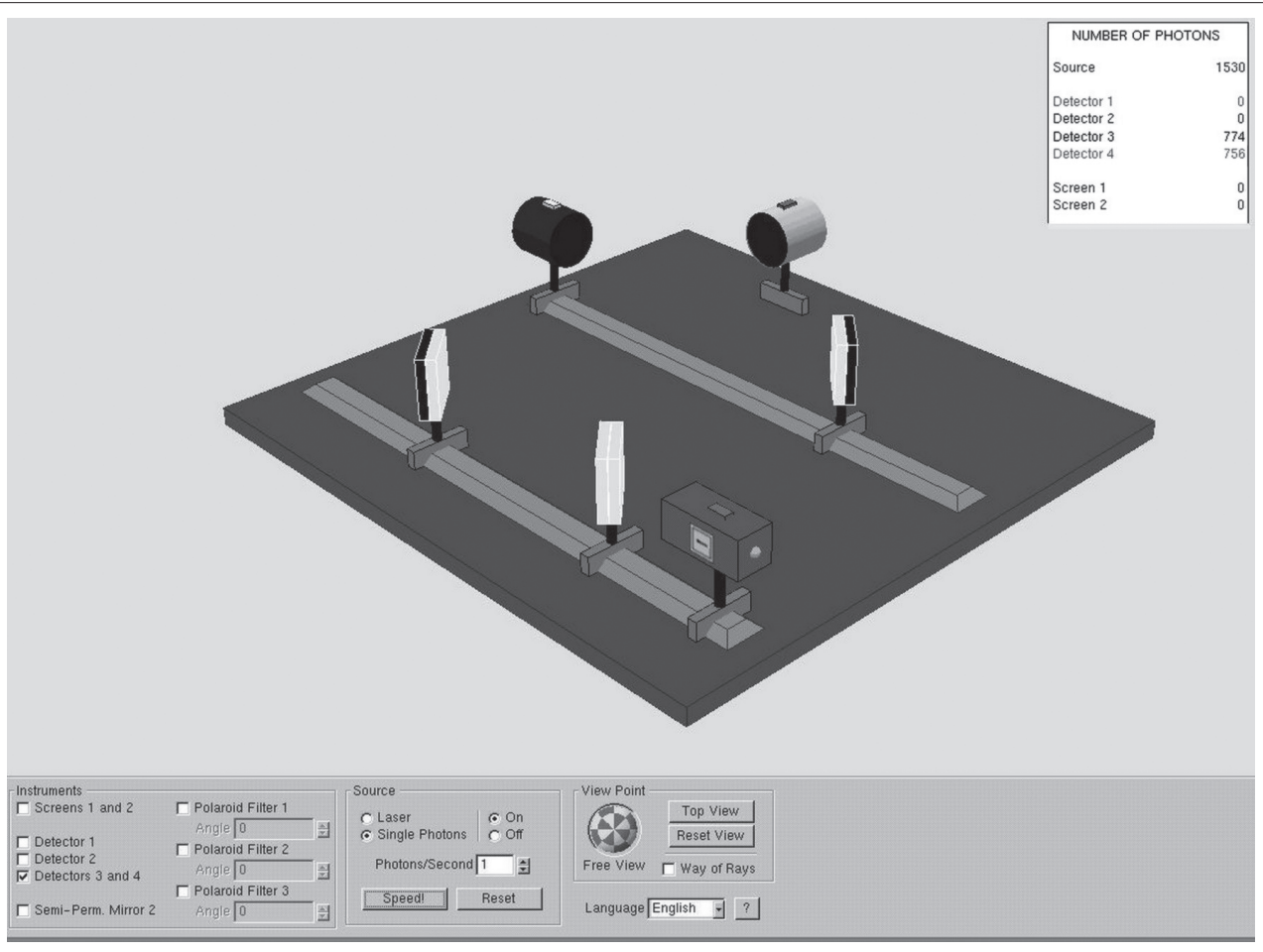

Fonte: http://www.if.ufrgs.br/ensfis_fernanda/index.php/main/inicial

Diálogo 01

(01) Diego: Vamos ligar. Tá, a situação que a gente tem é essa daí.

(02) Arnaldo: Aquela hora não era o azul (mais à esquerda) que tava mais... Não entendi. Não era o azul que, por ter interferência no...

(03) Diego: Aqui não! Era pra dar a mesma quantidade para os dois!

(04) Arnaldo: É possível inferir o caminho percorrido pelo fóton? Não, né?

(05) Diego: Eu só to tentando entender o que está acontecendo aqui porque pra mim, era pra ser $50 \%$ pra cada um.

(06) Arnaldo: Mas está normal. Aleatório, ó.

(07) Diego: Não! Olha o detector três e quatro... Ab! Agora melhorou um pouco a diferença. Ah, tá! Agora voltou. Ah, Tá! Agora está explicado. Agora está certinho. Está praticamente 50\%.

(08) Arnaldo: Existe uma probabilidade de ele ir pelo caminho A ou caminho $B$, mas a gente não pode falar nada sobre isso.

(09) Diego: É, só pode dizer que existe a chance, 50\% de chance pra cada caminho. Só isso.

(10) Arnaldo: Sim. (Arnaldo começa a escrever na folha) 
Pereira, A. P.; Ostermann, F.; Cavalcanti, C. J. H.

(11) Diego: Não, não, mas a gente tá viajando. Aqui ele está perguntando... Olha, lê essa outra pergunta. Eu acho que isso aqui não é o que a gente está respondendo. Se a gente pode inferir o caminho, a gente pode! Se ele é detectado pelo azul, obviamente ele seguiu o caminho... esse aqui. Se ele é detectado pelo laranja, ele obviamente seguiu esse caminho aqui. Nós podemos inferir o caminho percorrido pelo fóton. De acordo com o detector que pega ele.

Com base no diálogo acima, é possível inferir a maneira com que os estudantes organizam sua atividade. Enquanto Diego manipula o simulador virtual (fala 01), Arnaldo controla a atividade a partir da leitura dos itens do roteiro (fala 04). A forma autoritária com que Diego impõe o enunciado "Aqui não! Era pra dar a mesma quantidade para os dois?" (fala 03) sugere que ele esteja exercendo a função de parceiro mais capaz (VYGOTSKY, 1994), no sentido de se responsabilizar, também, pelas explicações dos fenômenos observados no softwa$r$, agindo de forma muito similar a um professor em uma aula expositiva.

A partir do enunciado 04, o diálogo é marcado por uma interanimação de vozes, que conduz a dupla em direção a uma resposta inadequada para a primeira questão. Eles concluíram (fala 08) que é impossível determinar o caminho percorrido pelos fótons, apesar de todas as evidências indicarem o contrário. Ao final do diálogo, no entanto, podemos perceber interações discursivas, não apenas entre os estudantes, mas também entre os estudantes e os instrumentos mediadores (roteiro). Após a leitura da segunda questão (item b), evidenciada no enunciado "Olha, lê essa outra pergunta." (fala 11), Diego foi capaz de reavaliar sua resposta. O enunciado "Não, não, mas a gente está viajando." mostra que, de alguma forma, a segunda questão organizou a ação de Diego de modo a evidenciar o caráter corpuscular do fenômeno, possibilitando, assim, a correção da resposta dada à primeira questão. A regulação da ação de Diego por parte do roteiro é facilmente identificável no enunciado "Eu acho que isso aqui não é o que a gente está respondendo. Se a gente pode inferir o caminho, a gente pode?".

É interessante notar que a segunda questão (item b) não responde à primeira (item a). A dinâmica do diálogo sugere, no entanto, que Diego não teria conseguido responder à primeira questão adequadamente sem antes ler o enunciado do item b. Esse tipo de interação discursiva (nesse caso, entre Diego e o roteiro), no qual não podemos definir claramente quem resolveu o problema assinalando um ou outro indivíduo isoladamente, consiste em um exemplo legítimo de distribuída "instrumental" da mente.

\section{Mente distribuída entre indivíduos no grupo}

Ao lidarem com as mesmas questões (itens a e b) enfrentadas por Diego e Arnaldo, Júlia, Paula e Alan (nomes fictícios) configuraram o interferômetro de acordo com a figura 1. Conforme mencionado anteriormente, nessa configuração os fótons emitidos pela fonte são detectados ora no detector mais à esquerda, ora no detector mais à direita. A interação entre esses três estudantes ocorreu da seguinte forma:

Diálogo 02

(01) Paula: É possivel interferir o caminho percorrido pelo fóton? Hã?

(02) Júlia: Como assim?

(03) Paula: Se tem como a gente tentar explicar o caminho que ofóton percorre. 
Um exemplo de "distribuição social da mente" ...

(04) Júlia: Não!

(05) Paula: É... Eu não me arriscaria. É, eu vou botar escrito 'eu não me arriscaria a explicar'.

(06) Júlia: Põe. Porque não tem como.

(07) Alan: Tu só consegue saber se é a metade do feixe.

(08) Júlia: Sim, mas dai é a probabilidade.

(09) Paula: É que não tem como o fóton se dividir.

(10) Júlia: É.

(11) Paula: Tu tem uma função de onda. Tu tem um monte de auto-estados. Tem só a probabilidade de percorrer os caminhos. Vou botar aqui ó, "não nos atrevemos a isto'.

(12) Alan: Não, mas tu consegue saber que é a metade da intensidade.

(13) Júlia: Sim. Isso sim. Mas tu não sabe dizer 'agora é esse caminho que ele tá percorrendo'. Tu não sabe dizer se ele tá indo pra cá ou se ele tá indo por aqui.

(14) Paula: Não, não é a metade da intensidade! Tu não sabe!

(15) Júlia: Metade, metade.

(16) Paula: Quando tu liga e tá saindo um fóton, não vai chegar metade da intensidade no anteparo e metade no outro.

(17) Júlia: É.

(18) Paula: O fóton ou vai chegar 'no' anteparo on 'no outro'.

(19) Júlia: Mas é que com o tempo, vai ser metade, metade.

A interanimação das vozes de Paula e de Júlia, mostrada no diálogo acima (falas 0106), levou o grupo a hesitar em atribuir um caminho ao fóton. $\mathrm{O}$ enunciado "Tu tem uma função de onda. Tu tem um monte de auto-estados. Tem só a probabilidade de percorrer os caminhos" (fala 11) sugere um certo domínio, por parte de Paula, com relação à teoria. Essa hesitação do grupo, evidenciada no enunciado "não nos atrevemos a isto" (fala 11), se deve, provavelmente, ao fato de os objetos quânticos não possuírem uma 'trajetória' bem definida, com posição e momentum linear, simultaneamente, bem definidos. É interessante notar que a participação de Alan (falas 07 e 12) provoca uma tensão no diálogo de modo a evidenciar, através da fala das meninas, o caráter corpuscular do fenômeno em questão. A aparente contradição entre Paula e Júlia faz com que o discurso de ambas se estenda por mais algumas linhas (falas 13-19).

$\mathrm{Na}$ sequência da atividade, após responderem os itens a e b, os estudantes recolocaram o segundo espelho semirrefletor, obtendo, assim, um padrão de interferência para fótons únicos, conforme mostra a Figura 2. Nessa configuração, todos os fótons emitidos pela fonte são detectados no detector mais à esquerda. Com relação a essa configuração, os estudantes tiveram de responder as seguintes perguntas: (c) É possível inferir o caminho percorrido pelo fóton? Explique. (d) Como você explicaria o padrão de interferência observado para fótons únicos? Explique.

Com relação a essas duas novas questões (itens c e d), nossa intenção era a de que os estudantes, a partir da observação da simulação, pudessem perceber que o padrão de interferência no interferômetro de Mach-Zehnder somente surge quando o caminho percorrido pelos fótons não pode mais ser determinado. Essa asserção está de acordo com a Interpretação da Complementaridade proposta por Bohr (PESSOA JR, 2005). A partir desse momento, a interação entre os estudantes ocorreu da seguinte forma: 
Pereira, A. P.; Ostermann, F.; Cavalcanti, C. J. H.

Figura 2. Interferência para fótons únicos.

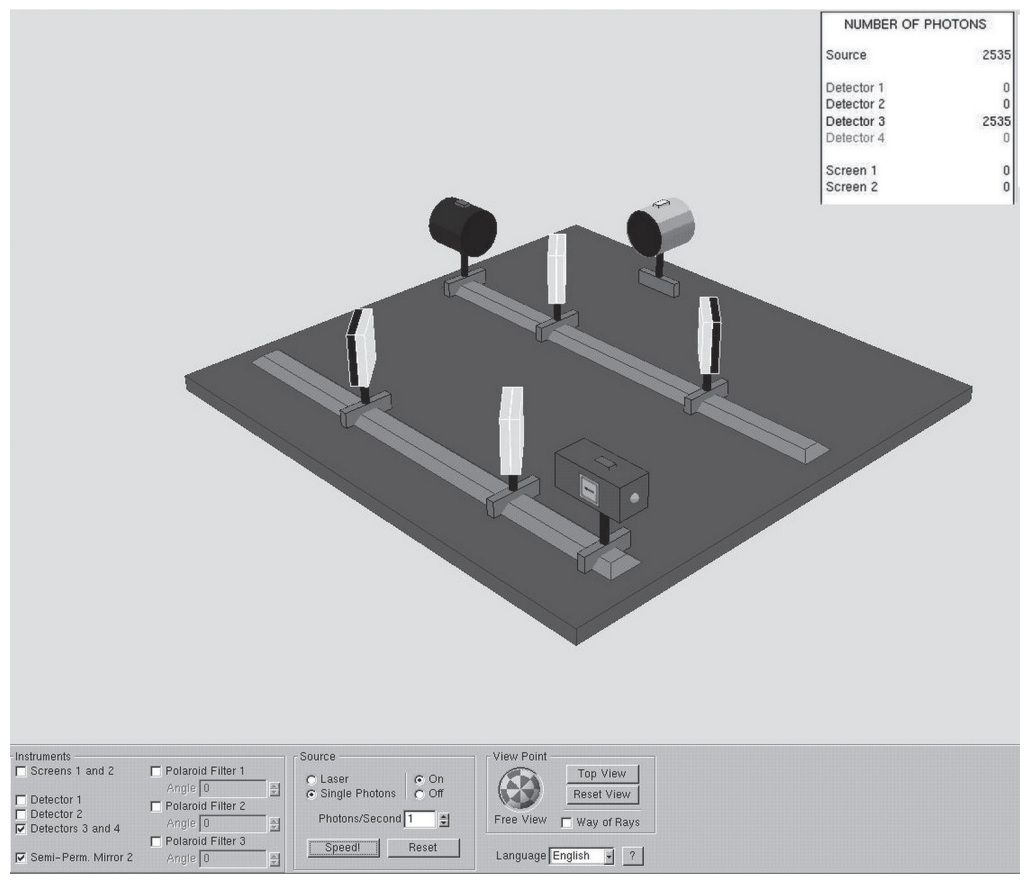

Fonte: http://www.if.ufrgs.br/ensfis_fernanda/index.php/main/inicial

Diálogo 03

(01) Paula: É possivel inferir o caminho percorrido pelo fóton?

(02) Júlia: Botei um semi-espelho ali.

(03) Paula: Pois é, eu não me atreveria também.

(04) Júlia: Tá, mas olha que estranho ele tá indo somente...

(05) Paula: Aqui é interferência construtiva.

(06) Júlia: Há é aquele caso que a gente viu antes.

(07) Paula: Só que tem uma questão forte agora, que é o regime monofotônico. Então é como se ele interferisse com ele mesmo.

(08) Júlia: Tá, mas aqui eu posso dizer.

(09) Paula: Não porque ele não tá indo sópara aquele detector. Ele tá interferindo construtivamente em um...

(10) Júlia: E destrutivamente em outro. Anota isso.

(11) Paula: Então ele tá percorrendo os dois caminhos, né? Vou botar 'não'.

(12) Alan: Acho que... não sei não. Dá pra criar dúvidas.

(13) Paula: $O$ que foi?

(14) Alan: Só voltando uma pergunta. Nessa questão aqui, ó. Pra responder essa, ele pergunta qual o caminho óptico do fóton. A gente vin que tinha um fóton aqui e fóton aqui. 
Um exemplo de "distribuição social da mente" ...

(15) Paula: Hu, bum.

(16) Alan: Então não é assim que a gente fez? É 2 Nd' mais 'd', mais 'd' pra cá. E aqui seria Nd... Não. Hum... 'd' mais 'd'...

(17) Paula: Sim.

(18) Alan: Sim se não tivesse esse espelho aqui, ne?

(19) Paula: Sim. Mas é que ele não está perguntando... Acho que ele só está perguntando... Porque como está em regime monofotônico, qual caminho que o fóton vai seguir. Se a gente teria como saber o caminho que ele vai seguir e explicar, vendo ele ser detectado no anteparo.

(20) Alan: Mas concorda que a gente sabe que ou ele vai por esse caminho aqui ou ele vai por esse caminho?

(21) Paula: Sim. Se ele for detectado no detector 1, ele foi pelo caminho um.

A partir do diálogo acima, é possível perceber que a interanimação das vozes de Paula e Júlia, inicialmente, determinou a dinâmica da atividade (falas 01-11). Paula exerce a função de parceira mais capaz, respondendo às dúvidas trazidas por Júlia. Ela percebe claramente o caráter dual do fenômeno quântico, conforme evidenciado no enunciado "Só que tem uma questão forte agora, que é o regime monofotônico. Então é como se ele interferisse com ele mesmo" (fala 07). O enunciado "Então ele está percorrendo os dois caminhos, nee?" (fala 11) mostra que ela corretamente considerou o fenômeno como sendo ondulatório, no sentido de que, nesse caso, não é possível atribuir uma trajetória ao objeto quântico (PESSOA JR., 2005).

A partir desse instante, o discurso é marcado pela participação decisiva de Alan. Ao se convidar para participar do diálogo (fala 12), Alan questiona a validade das explicações de Paula. Seu argumento, no entanto, é centrado na diferença de caminho óptico, assunto abordado pelo professor da disciplina em algumas aulas anteriores. Essa abordagem, no entanto, é um tanto inadequada para o problema em questão. A diferença de caminho óptico é essencial para entendermos o fenômeno de interferometria quântica, mas não nos ajuda em nada a determinar se o fenômeno pode ser considerado corpuscular ou ondulatório (PESSOA JR., 2005). O termo "Nd", empregado por Alan, refere-se à pequena diferença de caminho óptico introduzido pelos espelhos semirrefletores durante a refração da luz. O termo "d" é usado para designar a distância entre os espelhos e os semirrefletores.

Podemos observar que Paula tenta acompanhar o raciocínio de Alan, conforme mostram as falas 15 e 17. O enunciado "Sim. Mas é que ele não está perguntando..." (fala 19) explicita sua tentativa de desfazer a confusão estabelecida por Alan ao atacar o problema do caminho dos fótons. Essa discussão, no entanto, acabou organizando a ação de Paula, lançando luz sobre o problema que eles haviam debatido nas questões anteriores (itens a e b). Seu argumento, de que o problema não envolve a diferença de caminho óptico, de alguma forma explicitou a correlação entre o acionamento dos detectores e o caminho percorrido pelo fóton, conforme mostra o enunciado "Porque como está em regime monofotônico, qual caminho que o fóton vai seguir. Se a gente teria como saber o caminho que ele vai seguir e explicar, vendo ele ser detectado no anteparo" (fala 19). É interessante notar que o grupo já havia definido a resposta para a primeira questão (item a). Somente após a discussão da terceira questão (item c) eles puderam reavaliar sua resposta. Com base nos enunciados de Paula e Alan, podemos concluir que nenhum deles teria conseguido formular a versão final da resposta dada à primeira questão (item a) sem a ajuda um do outro. Esse exemplo, no qual não podemos determinar quem respondeu à pergunta, assinalan- 
Pereira, A. P.; Ostermann, F.; Cavalcanti, C. J. H.

do um ou outro indivíduo isoladamente, consiste em mais um exemplo empírico de cognição distribuída; nesse caso, distribuição social da mente.

\section{Considerações finais}

No presente trabalho, apresentamos, no âmbito do ensino de física quântica, dois exemplos sobre o fenômeno da distribuição social da mente em uma tarefa conduzida por um grupo de graduandos em física e mediada por um interferômetro virtual de Mach-Zehnder (OSTERMANN; PRADO; RICCI, 2006). Inicialmente, esboçamos alguns aspectos relevantes da teoria de Vygotsky que sustentam a afirmação de que a mente "se estende além da pele" (WERTSCH, 1991b). A seguir, apresentamos dois episódios em que o fenômeno da distribuição social da mente é facilmente identificável, e analisamos em que medida as interações entre os estudantes (plano interpsicológico) possibilitaram a realização da tarefa proposta.

Com base nesses dois exemplos, podemos observar que alguns enunciados são marcados por uma interanimação de vozes análoga àquelas que definem o que alguns teóricos chamam de cognição distribuída (WERTSCH, 1991a, 1998b; COLE; WERTSCH, 1996; HUTCHINS, 1995, 2008). Em alguns debates mais polêmicos, a construção colaborativa de significados, ao longo da atividade, surgiu através de um processo complexo de interanimação de vozes no qual é impossível identificar quem respondeu às questões do roteiro. Em outras palavras, foi o grupo como um todo (dupla ou trio) que, no plano interpsicológico, desempenhou a função de achar as respostas adequadas, atuando como um sistema integrado, e não como um conjunto de indivíduos isolados. Na maioria dos casos, essa interanimação de vozes caracterizou-se pela construção deliberada de argumentos confusos, por parte de um dos integrantes do grupo, que, de uma forma ou de outra, orientou o pensamento e a ação do colega.

Os resultados encontrados no presente estudo mostram a relevância das atividades em grupo desenvolvidas nas aulas de ciências. No plano interpsicológico ou social, as interanimações de vozes, presentes nas atividades em grupo, possibilitam a construção de novos significados, processo estreitamente vinculado à noção de zona de desenvolvimento proximal proposta por Vygotsky (1994). Não se trata, no entanto, de um estudante mais experiente simplesmente ajudar o colega menos capacitado. Atuando como um sistema integrado, o grupo como um todo é capaz de resolver certos problemas que nem o mais capaz dos companheiros consegue resolver isoladamente. Trata-se, portanto, de uma via de mão dupla, onde todos os membros do grupo se beneficiam com a atividade. Nossa atividade, em particular, possibilitou a resolução colaborativa de problemas, processo de fundamental importância tanto do ponto de vista da própria Ciência como do ponto de vista da Educação Científica e Tecnológica. 
Um exemplo de "distribuição social da mente" ...

\section{Referências}

ADAMS, S. Quantum bombing reality. Physics Education, London, v. 33, n. 6, p. 378-385, 1998.

BAKHTIN, M. M. Speech genres and other late essays. 6. ed. Austin: University of Texas Press, 1996.

BAKHTIN, M. M.; VOLOCHINOV, V. N. Marxismo e filosofia da linguagem: problemas fundamentais do método sociológico na ciência e na linguagem. 12. ed. São Paulo: Hucitec, 2006.

BATESON, G. Steps to an ecology of mind: a revolutionary approach to man's understanding of himself. New York: Ballantine, 1972.

BRUNER, J. Realidade mental, mundos possíveis. Porto Alegre: Artes Médicas, 1997.

COLE, M.; WERTSCH, J. V. Beyond the individual-social antinomy in discussions of Piaget and Vygotsky. Human Development, Berkeley, v. 39, n. 5, p. 250-256, 1996.

GEERTZ, C. A interpretação das culturas. Rio de Janeiro: LTC, 1989.

HUTCHINS, E. Cognition in the wild. Cambridge: MIT Express, 1995.

. The role of cultural practices in the emergence of modern human intelligence.

Philosophical Transactions of the Royal Society B, London, v. 363, n. 1499, p. 2011-2019, 2008.

LEMKE, J. L. Articulating communities: sociocultural perspectives on science education. Journal of Research in Science Teaching, Hoboken, v. 38 n. 3, p. 296-316, 2001.

MOORE, J. L.; ROCKLIN, T. R. The distribution of distributed cognition: multiple interpretations and uses. Educational Psychology Review, New York, v. 10, n.1, p. 97-113, 1998.

MÜLLER, R.; WIESNER, H. Teaching quantum mechanics on an introductory level. American Journal of Physics, Melville, v. 70, n. 3, p. 200-209, 2002.

OSTERMANN, F; PRADO, S. D.; RICCI, T. S. F. Desenvolvimento de um software para o ensino de fundamentos de física quântica. A Física na Escola, São Paulo, v. 7, n. 1, p. 22-25, 2006.

PEREIRA, A. P. Fundamentos de física quântica na formação de professores: uma análise de interações discursivas em atividades centradas no uso de um interferômetro virtual de Mach-Zehnder. 2008. 139f. Dissertação (Mestrado em Ensino de Física) Instituto de Física, Universidade Federal do Rio Grande do Sul, Porto Alegre, 2008.

PEREIRA, A. P.; CAVALCANTI, C. J. H.; OSTERMANN, F. Concepções relativas à dualidade onda-partícula: uma investigação na formação de professores de física. Revista Electrónica de Enseñanza de las Ciencias, Vigo, v. 8, n. 1, p. 72-92, 2009.

O ensino de física quântica na perspectiva sociocultural: uma análise de um debate entre futuros professores mediado por um interferômetro virtual de Mach-Zehnder. Revista Electrónica de Enseñanza de las Ciencias, Vigo, v. 8, n. 2, p. 376-398, 2009 a. 
Pereira, A. P.; Ostermann, F.; Cavalcanti, C. J. H.

PEREIRA, A. P.; CAVALCANTI, C. J. H.; OSTERMANN, F. On the use of a virtual Mach-Zehnder interferometer in the teaching of quantum mechanics. Physics Education, Bristol, v. 44, n. 3, p. 281-291, 2009b.

A ocorrência de 'fala privada' entre adultos: uma estratégia analítica para o estudo das funções intrapsicológicas no ensino de ciências. Ensaio - Pesquisa em Educação em Ciências, Belo Horizonte, v. 13, n. 1, p. 105-120, 2011.

PESSOA JR., O. Interferometria, interpretação e intuição: uma introdução conceitual à física quântica. Revista Brasileira de Ensino de Física, São Paulo, v. 19, n. 1, p. 27-48, 1997.

Conceitos de física quântica. 2. ed. São Paulo: Livraria da Física, 2005.

SCARANI, V:; SUAREZ, A. Introducing quantum mechanics: one-particle interferences. American Journal of Physics, Melville, v. 66, n. 8, p. 718-721, 1998.

THARP, R. G..; GALLIMORE, R. Rousing minds to life: Teaching, learning, and schooling in social context. New York: Cambridge University Press, 1988.

VYGOTSKY, L. S. The problem of the cultural development of the child. Journal of Genetic Psychology, Washington, v. 36, n. 3, p. 415-434, 1929.

A formação social da mente: o desenvolvimento dos processos psicológicos superiores. 5. ed. São Paulo: Martins Fontes, 1994.

Historia del desarrollo de las funciones psíquicas superiores. In: Obras escogidas. Madrid: Visor, 1996. v. 3. p. 11-340.

Pensamento e linguagem. São Paulo: Martins Fontes, 1998.

WERTSCH, J. V. From social interaction to higher psychological processes: a clarification and application of Vygotsky's theory. Human Development, Berkeley, v. 51, n.1, p. 66-79, 1979.

Vygotsky and the social formation of the mind. Cambridge: Harvard University Press, 1985.

A sociocultural approach to socially shared cognition. In: RESNICK, L.; LEVINE, J.; TEASLEY, S. (Org.). Perspectives on socially shared cognition. Washington: American Psychological Association, 1991a. p. 85-100.

Voices of the mind: a sociocultural approach to mediated action. Cambridge: Harvard University Press, 1991b.

A necessidade da ação na pesquisa sociocultural. In: WERTSCH, J. V.; DEL RÍO, P.; ALVAREZ, A. (Org.). Estudos socioculturais da mente. Porto Alegre: Artmed, 1998a. p. 56-71.

Mind as action. New York: Oxford University Press, 1998b.

Artigo recebido em 01/08/2011. Aceito em 02/12/2011. 